\title{
Correction to: The middle Miocene palynofloras of the Salihpaşalar lignite mine (Yatağan Basin, Southwest Anatolia): environmental characterisation and comparison with palynofloras from adjacent basins
}

\author{
Johannes M. Bouchal ${ }^{1,2}$
}

Published online: 23 November 2019

(C) Senckenberg Gesellschaft für Naturforschung and Springer-Verlag GmbH Germany, part of Springer Nature 2019

Correction to: Palaeobiodiversity and Palaeoenvironments. https://doi.org/10.1007/s12549-018-0345-0

There was an error in the caption of Fig. 10, below the correct caption:

Fig. 10 LM overview (a, d, g, j, m ), SEM overview (b, e, h, k, n) and SEM detail (c, f, i, l, o, p ) micrographs of Amaranthaceae, Droseraceae, Polygonaceae, Sapotaceae and Oleaceae pollen. a-c Drosera sp. (S153636). d-f Persicaria sp./Persicarioipollenites pliocenicus (S153634). g-i Amaranthaceae gen. indet. 3(S153636). j-l Sapotaceae gen. indet. (S153631), EV. m-o Oleaceae gen. indet. 1 (S153623), EV. Abbreviations: PV, polar view; EV, equatorial view. Scale bars, $10 \mu \mathrm{m}(\mathrm{a}, \mathrm{b}, \mathrm{d}, \mathrm{e}, \mathrm{g}, \mathrm{h}, \mathrm{j}, \mathrm{k}, \mathrm{m}, \mathrm{n}), 1 \mu \mathrm{m}$ (c, f, i, l, o)

This erratum refers to a contribution to the special issue "Taking the Orient Express? The role of Anatolia in mediterranean Neogene palaeobiogeography".

The online version of the original article can be found at https://doi.org/ 10.1007/s12549-018-0345-0

Johannes M. Bouchal

johannes.bouchal@nrm.se

1 Department of Palaeobiology, Swedish Museum of Natural History, 10405 Stockholm, Sweden

2 Department of Palaeontology, University of Vienna, 1090 Vienna, Austria 